\title{
Radiation Induced Grafting of Viscose Rayon Fabrics with Some Acrylic Acid Derivatives and Styrene
}

\author{
Mahmoud Barakat Foad Ahmed Barakat ${ }^{*}$, Kariman Mohame El-Salmawy², \\ Abdel-Hamid Hussein Zahran² \\ ${ }^{1}$ Nuclear and Radiological Control Authority, Cairo, Egypt \\ ${ }^{2}$ National Center of Radiation Research and Technology, Atomic Energy Authority, Cairo, Egypt \\ Email: *mbarakat49@yahoo.com
}

How to cite this paper: Barakat, M.B.F.A., El-Salmawy, K.M. and Hussein Zahran, A.H. (2017) Radiation Induced Grafting of Viscose Rayon Fabrics with Some Acrylic Acid Derivatives and Styrene. Open Journal of Polymer Chemistry, 7, 1-18.

https://doi.org/10.4236/ojpchem.2017.71001

Received: February 20, 2017

Accepted: February 25, 2017

Published: February 28, 2017

Copyright (ङ 2017 by authors and Scientific Research Publishing Inc. This work is licensed under the Creative Commons Attribution International License (CC BY 4.0).

http://creativecommons.org/licenses/by/4.0/

\begin{abstract}
Radiation induced grafting of viscose rayon fabrics, consisting mainly of cellulose fibers, with some acrylic acid derivatives, namely methyl acrylate, acrylamide and acrylonitrile, and also styrene, has been studied. The resultant graft yields have been determined as a function of the applied different experimental parameters. The impact of the graft yields on the physicochemical properties of viscose rayon fabrics such as swelling, moisture absorption, tensile strength, elongation at break, crease recovery angle and also dyeing ability of the grafted fabrics, has been also studied.
\end{abstract}

\section{Keywords}

Radiation Graft Copolymerization, Viscose Rayon, Gamma Irradiation, Monomers, Styrene, Acrylic Acid Derivatives

\section{Introduction}

Radiation induced grafting of vinyl monomers has been successfully applied to modify the chemical and/or physical properties of polymers or textile fibers [1] [2]. Properties that can be introduced into the fibers by radiation grafting involve enhancement of dyeing ability and resistance to the effect of oil, water, dirt and microorganisms [3].

It has been reported that one of the major drawbacks of viscose rayon is its poor strength and low resistance to weathering and these drawbacks can be overcome by suitably modifying viscose rayon by grafting with some monomers [4]. In general modification of the properties of textile fibers could lead to products of desirable properties technically or economically. For example Nylon-6 
fabric grafted with acrylamide showed a significant increase in hydrophilic properties in terms of moisture regain and water absorption as well as good dye affinity for selected dye stuffs [5]. Radiation induced grafting of acrylic acid onto nylon- 6 gave fibers with better dyeing ability [6]. Moreover, radiation induced grafting of vinyl pyrrolydone onto nylon- 6 produced fibers with higher moisture absorption and better tensile properties [7].

In a previous publication, radiation induced grafting of viscose rayon fabrics with acrylic acid has been carried out. The impact of the graft yield on the physical or chemical properties of the fabrics has been also studied [8].

In the present work, radiation induced grafting of viscose rayon fabric samples with methyl acrylate, acrylamide, acrylonitrile or styrene, used as monomers under different experimental conditions, has been carried out in order to determine the agreeable grafting conditions. The changes occurring in the physicochemical properties of the grafted viscose rayon fabrics were also investigated.

\section{Materials and Experimental Techniques}

\subsection{Materials}

\subsubsection{Pure Untreated Viscose Rayon Fabrics}

Viscose rayon fabric samples were obtained from Misr Helwan Co., Helwan, Egypt. Stripes of viscose rayon fabrics $(7 \mathrm{~cm}$ width) were extracted, for 30 minutes, with diethyl ether then with ethanol in a Soxhlet apparatus and finally were washed with distilled water. The extracted samples were then dried in a vacuum oven at $60^{\circ} \mathrm{C}$ until constant weight and kept in a vacuum desciccator until used.

\subsubsection{Monomers}

Methyl acrylate was obtained from B.D.H. Poole, GB, stabilized with $0.02 \% \mathrm{Me}-$ thoxy phenol. Before use it was purified by fractional distillation under reduced pressure in presence of inert atmosphere.

Acrylonitrile was obtained from B.D.H. Chemicals Ltd., GB, stabilized with $0.005 \%$ Methoxy phenol. It was purified by fractional distillation under reduced pressure and inert atmosphere.

Acrylamide: m.p. $84.5^{\circ} \mathrm{C}$, was obtained from Merck Chemical Co., Germany, and was used without further purification.

Styrene was obtained from J. T. Baker Chem. Co. and was purified by shaking with $20 \%$ sodium hydroxide solution then washed with water and finally it was dried over anhydrous sodium sulfate overnight. It was purified by distillation under reduced pressure and the distillate was collected and kept in a desciccator until used. Fresh styrene portions were always used.

\subsubsection{Other Chemicals}

AnalaR methanol was obtained from Prolabo, Rhone, France. Pure Dimethyl formamide (DMF) was obtained from Veb-Laborchemie, Germany, and was used without further purification. AnalaR benzene was obtained from BDH, GB and was used without further purification.

The dye types used were: the direct dye 23 diamine fast scarlet 485, C.I. 2916 
and the disperse dye Celliton pink FF3 and were obtained from BASF, Germany. The basic dye Sandocryl blue B-3 Gr, C.I. 41004 was obtained from Sandoz Germany.

\subsection{Experimental Procedures}

The factors affecting the radiation induced graft yields of different monomers on to viscose rayon fabric samples were studied in detail. Viscose rayon fabric samples were dipped in a liquid phase consisting of a certain amount of the used monomer in two different solvent systems and then were subjected to certain doses of gamma radiation. Detailed sample preparation procedures, gamma irradiation conditions, treatment of irradiated samples and determination of graft yield (\%) were the same as described in detail in a previous publication [8].

The changes occurring in some physicochemical properties, of the viscose rayon fabric samples grafted with different monomers, namely, moisture absorption, swelling, crease tensile strength and elongation at break recovery angle, as well as dye uptake and were followed, on increasing the graft yields on the modified viscose rayon samples.

\section{Results and Discussions}

\subsection{Graft Yields of Different Monomers onto Viscose Rayon Fabric Samples under Different Experimental Conditions}

\subsubsection{Effect of Solvent Composition}

Two solvent systems have been used in the present work namely methanol/water and DMF/water, on using acrylic acid monomers and methanol/benzene on using styrene monomer.

The graft yields (\%) on grafting viscose rayon fabrics with different monomers namely, methyl acrylate, Acrylamide, Acrylonitrile and styrene, are shown in Figures 1-6.

On using methyl acrylate monomer the best graft yield was obtained on using $50 \%$ methanol in water as could be observed in Figure 1, while on using DMF/ water solvent mixture, extensive homopolymer formation occured as the percent water was increased up to 50\% water, as could be observed in Figure 2. Good graft yields were obtained on increasing the water per cent above $50 \%$.

In case of Acrylamide the graft yield (\%) slightly decreased until 30\% water, in both solvents was used, and the graft yield remained afterwards almost unchanged on increasing the water content in solvent used, as could be observed from the data shown in Figure 3 and Figure 4.

On using acrylonitrile monomer, in both solvent systems, the maximum graft yields of acrylonitrile onto viscose rayon were observed on using $30 \%-40 \%$ water in solvent and remained after that almost the same on increasing the water content in the solvent, as could be observed in Figure 5.

In case of styrene monomer the best graft yields were obtained at methanol concentration $80 \%$ in benzene/methanol solvent as could be observed in the data shown in Figure 6. 


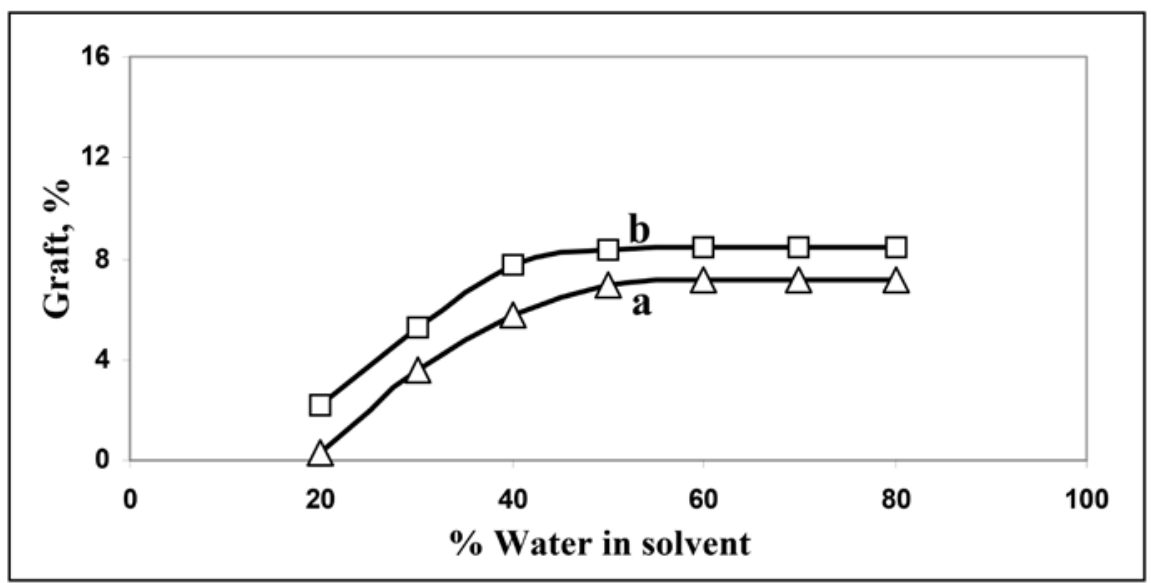

Figure 1. Change of the graft yield (\%) of methyl acrylate onto viscose rayon fabric in Methanol- $\mathrm{H}_{2} \mathrm{O}$ solvent system of varying composition Monomer concentration: a. $2 \%$; b. 5\% Irradiation dose: $1.0 \mathrm{kGy}$.

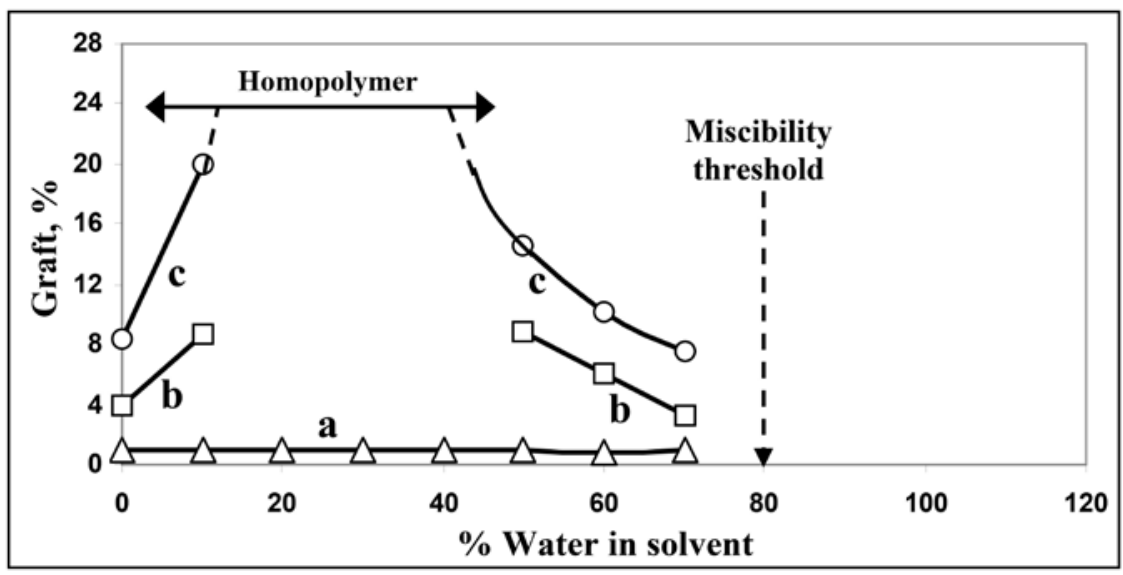

Figure 2. Change of the graft yield (\%) of methyl acrylate onto viscose rayon fabric in DMF: $\mathrm{H}_{2} \mathrm{O}$ solvent system of varying composition. Monomer concentration: a. 2\%; b. 5\%; c. $7 \%$ Irradiation dose: $1.0 \mathrm{kGy}$.

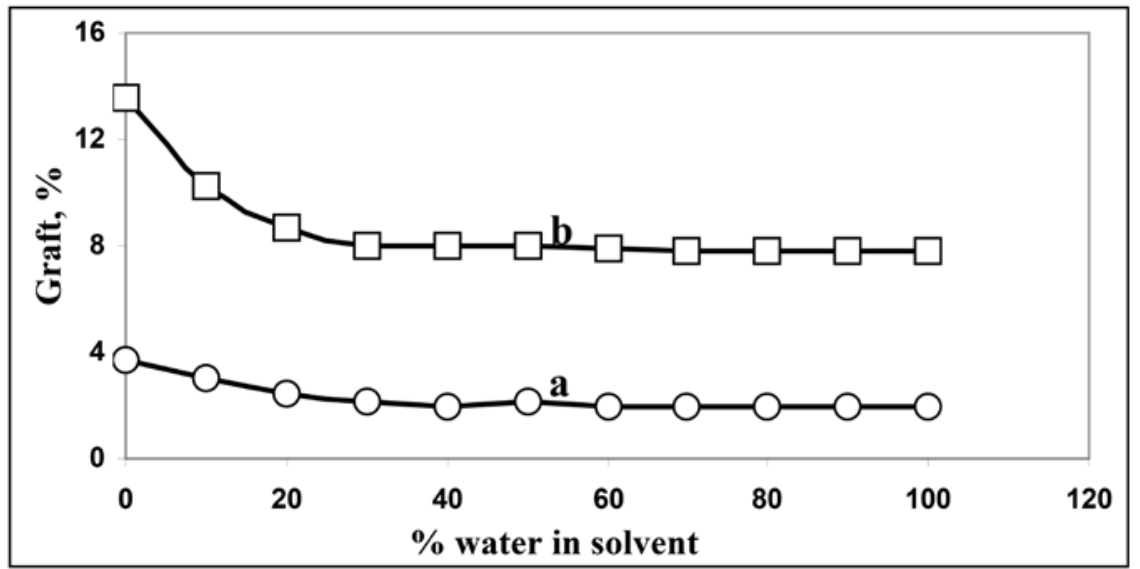

Figure 3. Change of the graft yield (\%) of acrylamide onto viscose rayone fabric using two different monomer concentrations in methanol-water solvent system of varying composition; a. 3\% Acrylamide; b. 9\% Acrylamide Irradiation dose: $10 \mathrm{kGy}$. 


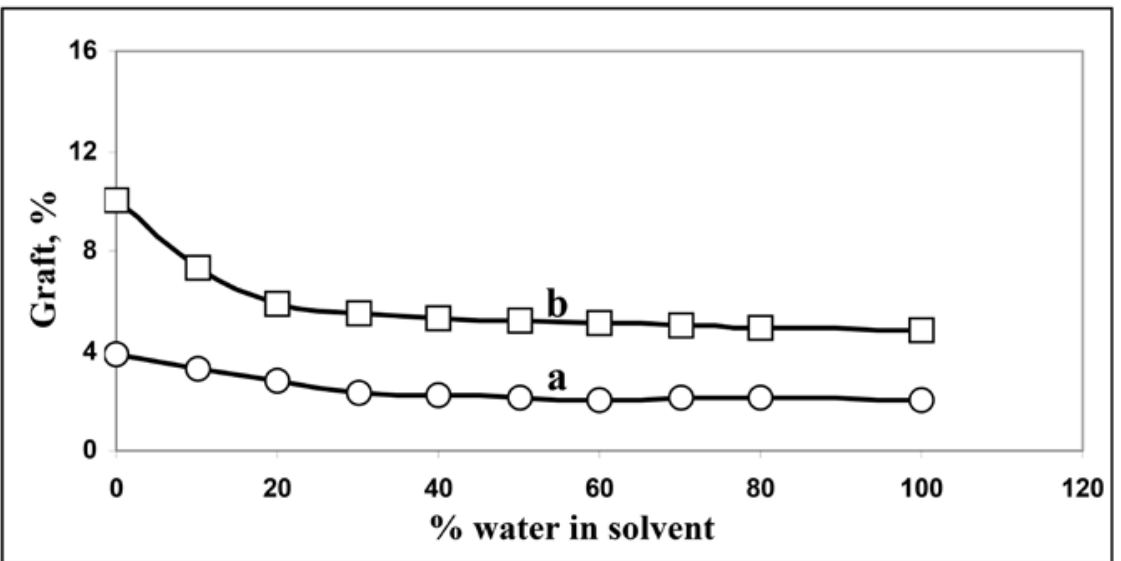

Figure 4. Change of the graft yield (\%) of acrylamide onto viscose rayon fabric in DMF$\mathrm{H}_{2} \mathrm{O}$ solvent system of varying composition using two different monomer concentrations; a.3\% Acrylamide; b. 9\% Acrylamide Irradiation dose: $10 \mathrm{kGy}$.

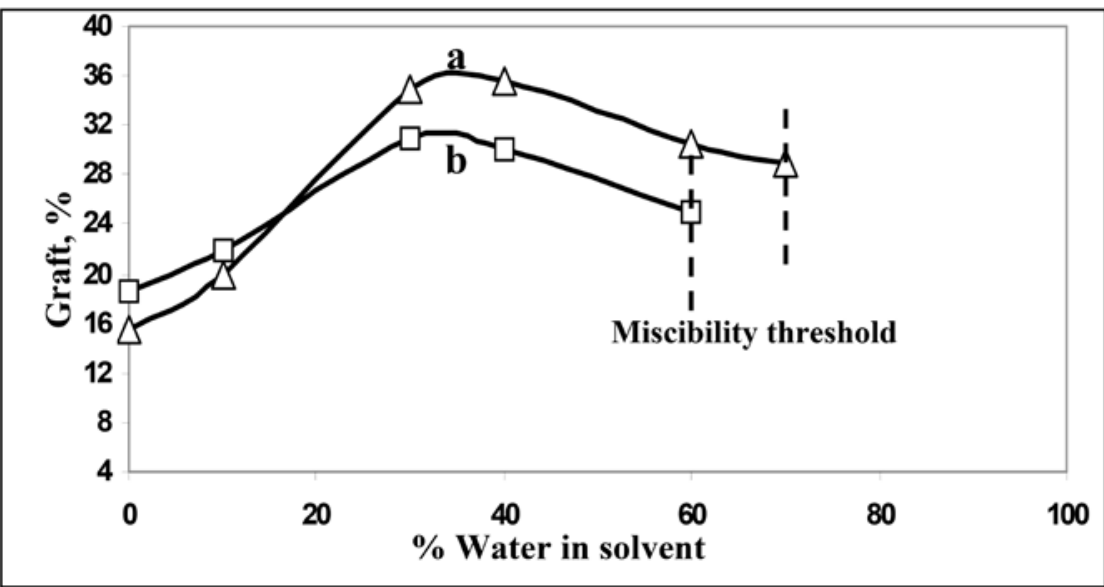

Figure 5. Change of graft yield of acrylonitrile (\%) onto viscose rayon in different solvent systems. a. Methanol-waterb DMF-water Irradiation dose: $10 \mathrm{kGy}$ Monomer concentration: $10 \%$.

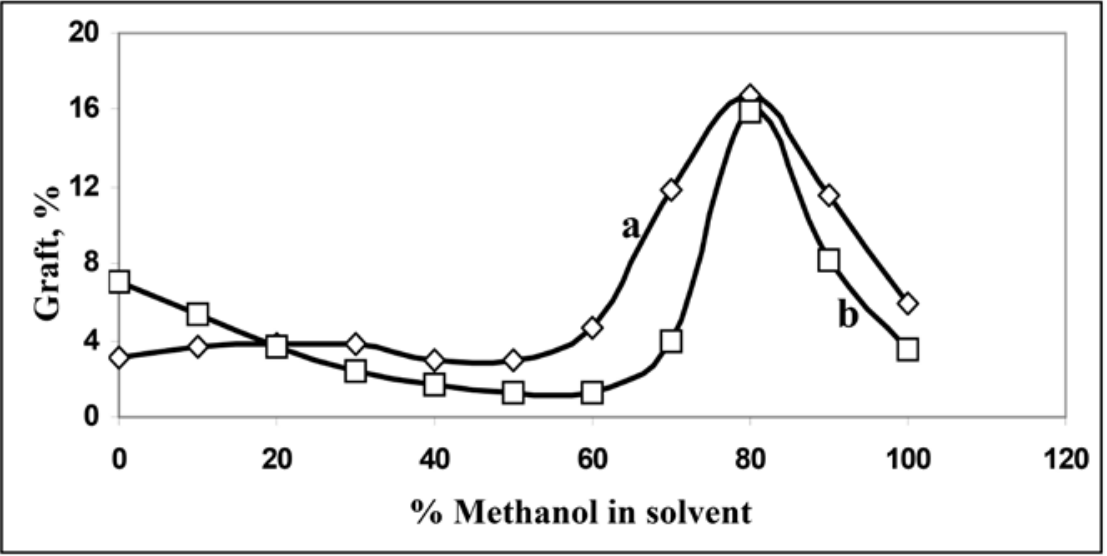

Figure 6. Change of the percent grafting yield of styrene onto viscose rayon in different Benzene-Methanol solvent compositions. Irradiation dose: $16 \mathrm{kGy}$ Monomer concentration in Liquid phase: 10\% Dose rates: a. $0.075 \mathrm{~Gy} / \mathrm{s}$; b. $0.225 \mathrm{~Gy} / \mathrm{s}$. 


\subsubsection{Effect of Monomer Concentration}

On using mehyl acrylate monomer, the best graft yields (\%) of methyl acrylate onto viscose rayon, using two solvent systems, were obtained at monomer concentrations greater than 7\% as could be observed in Figure 7.

On using acrylamide, good graft yields (about 15\%) were obtained on using $12 \%$ of monomer in methanol/water solvent mixture and on using about $15 \%$ monomer in DMF/water mixture, as could be observed in Figure 8.

In case of acrylonitrile monomer, the change of the graft yield on using different monomer concentrations, in the two solvent systems, is shown in Figure 9. Thus, on using $10 \%-15 \%$ monomer in the solvent system, good grafting yields were obtained with low homopolymer formation. Higher homopolymer formation occurred on using higher monomer concentrations.

On using styrene monomer in grafting with viscose rayon in benzene/methanol solvent system (20:80), it could be observed that good grafting yields were obtained on using 10\% - 12\% monomer concentration, as shown in Figure 10.

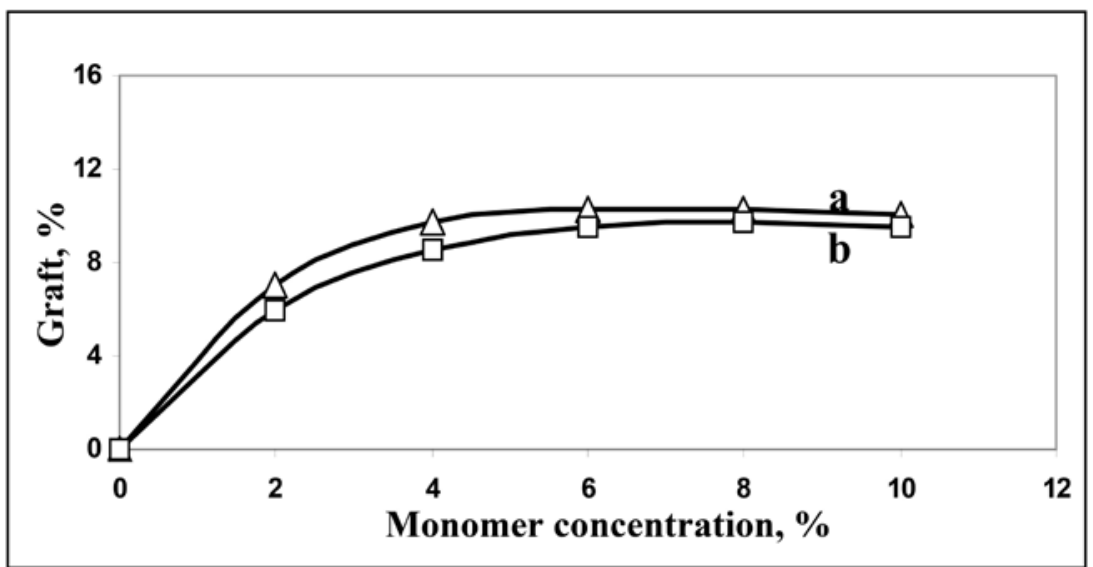

Figure 7. Change of the graft yield (\%) of methyl acrylate onto viscose rayon fabric with monomer concentration using two different solvent systems; a. Methanol $\mathrm{H}_{2} \mathrm{O}$ : (40:60) b. DMF- $\mathrm{H}_{2} \mathrm{O}$ : (40:60) Irradiation dose: $1.0 \mathrm{kGy}$.

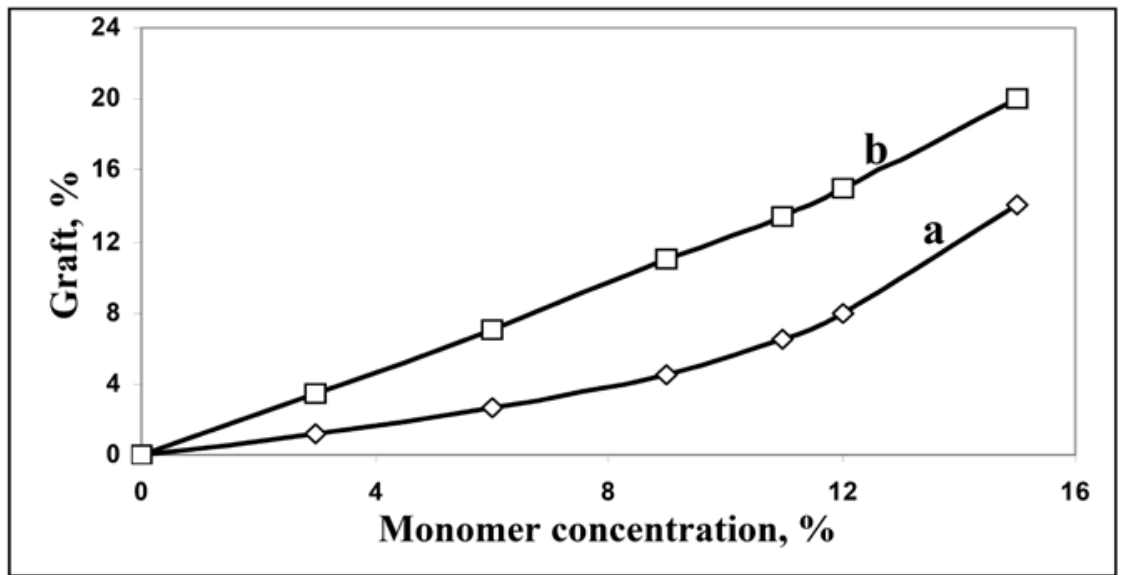

Figure 8. Change of the graft yield (\%) of acrylamide onto viscose rayon fabric with monomer concentration using two solvent systems: a. Methanol-water; (80:20) b. DMFwater (80:20) Irradiation dose $10 \mathrm{kGy}$. 


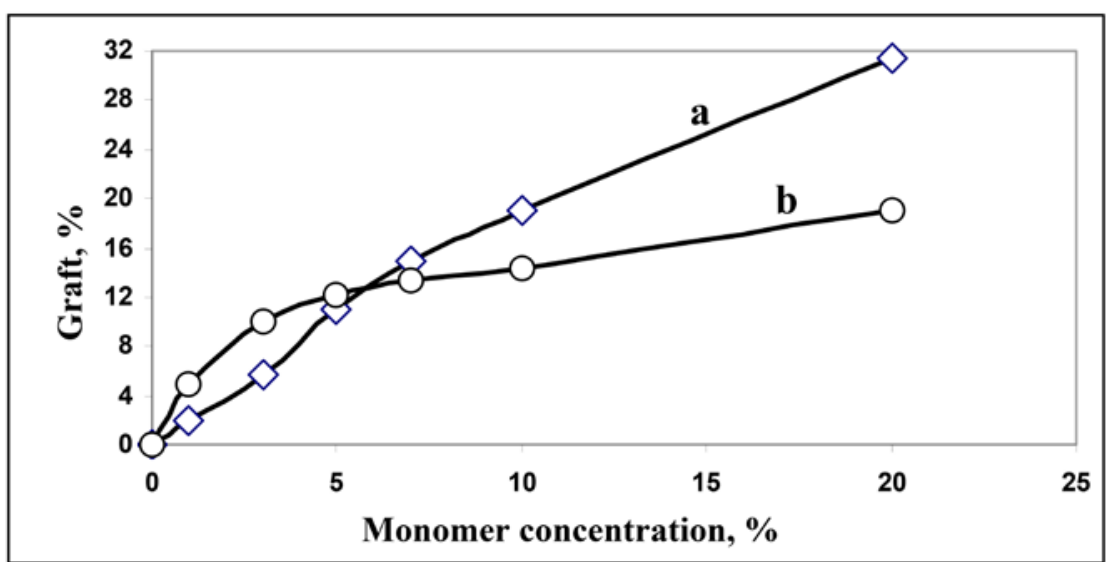

Figure 9. Change of the graft yield of acrylonitrile onto viscose rayon fabric with monomer concentration using different solvent systems: a. Methanol-Water: (70:30) b. DMFWater: (70:30) Irradiation dose: $10 \mathrm{kGy}$.

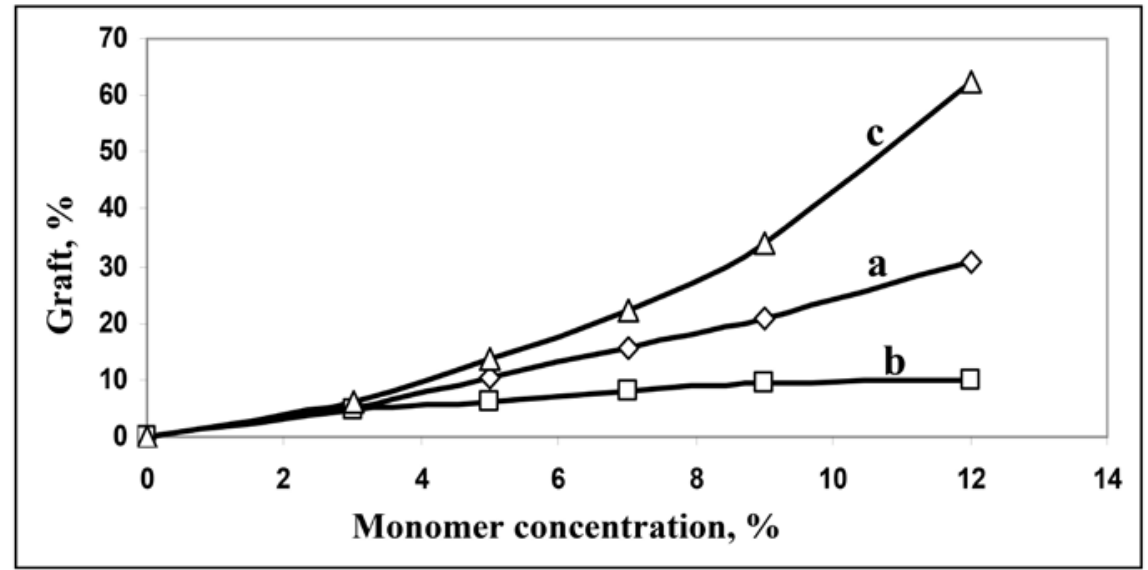

Figure 10. Change of the percent grafting yield of styrene onto viscose rayon fabric with monomer concentration at different solvent composition. a. Benzene-methanol; 90:10 b. Benzene-methanol 80:20; c. Benzene-methanol 20:80; Irradiation dose: 16 kGy.

\subsubsection{Effect of Irradiation Dose}

On using methyl acrylate monomer the best graft yields were obtained at doses less than $1 \mathrm{kGy}$ on using methanol-water solvent system (40:60) and 10\% monomer concentration, as shown in Figure 11. On using DMF-water solvent system the best graft yields were obtained on using 7\% monomer and about $3 \mathrm{kGys}$ irradiation dose as could be observed in Figure 12.

On using acrylamide monomer, with the two solvents used, the best graft yields were obtained at irradiation doses greater than $7 \mathrm{kGys}$ as shown in Figure 13.

In case of using acrylonitrile monomer, in both solvent systems, the best graft yields were obtained at irradiation doses greater than $8 \mathrm{kGys}$ as could be observed from the data shown in Figure 14. Using higher irradiation doses did not significantly increase the graft yield.

On using styrene as monomer in benzene-methanol solvent system, the graft yields were found to increase linearly with irradiation dose up to $20 \mathrm{kGys}$, as 


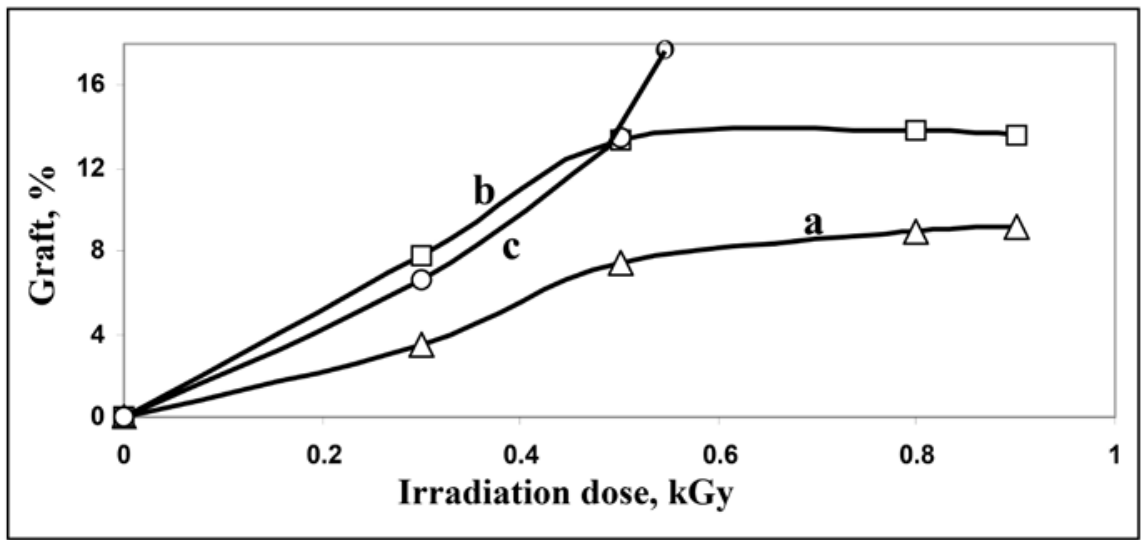

Figure 11. Change of the graft yield (\%) of methyl acrylate onto viscose rayon fabric in Methanol-Water solvent system (40:60) with irradiation dose and using different monomer concentrations: a. $5 \%$; b, $10 \%$; c. $20 \%$.

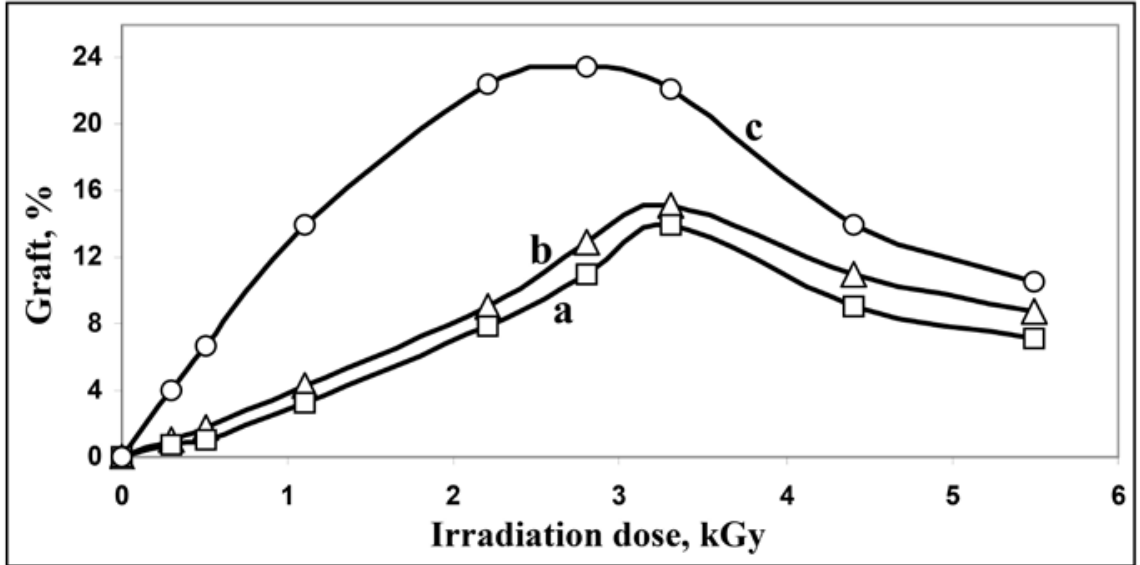

Figure 12. Change of the graft yield \% of methyl acrylate monomer onto viscose rayon fabric with irradiation dose using three different monomer concentrations in DMF- $\mathrm{H}_{2} \mathrm{O}$ solvent system (40:60) Monomer concentration: a. 3\%; b. 5\%; c. $7 \%$.

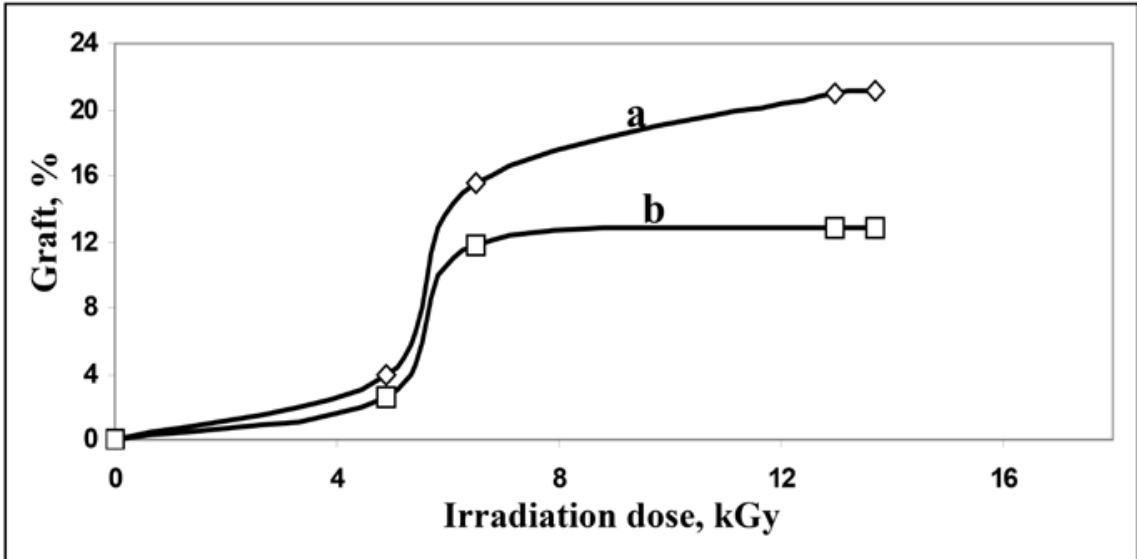

Figure 13. Change of the grafting yield (\%) of acrylamide onto viscose rayon fabric with irradiation dose using different solvent systems: a. Methanol-water (80:20); b. DMF-water (80:20) Monomer concentration: 9\%. 


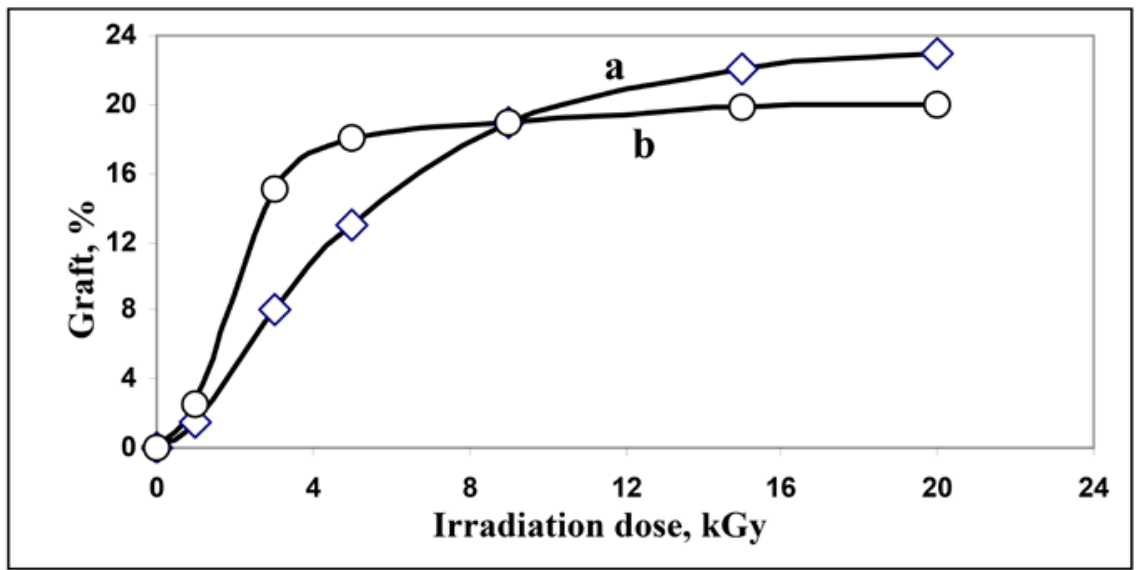

Figure 14. Change of the graft yield (\%) of acrylonitrile onto viscose rayon fabric on increasing irradiation dose using different solvent systems: a. Methanol- $\mathrm{H}_{2} \mathrm{O}$ : (70:30); b. DMF- $\mathrm{H}_{2} \mathrm{O}$ : (70:30) Monomer concentration: $0 \%$.

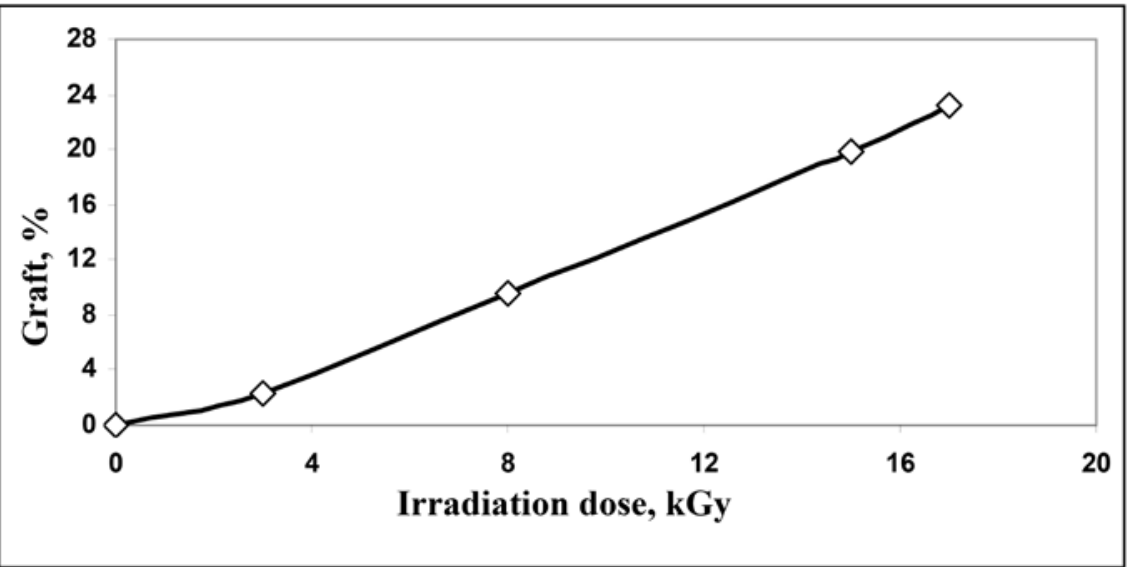

Figure 15. Change of the graft yield (\%) of styrene onto viscose rayon fabric on increasing irradiation dose. solvent system: Benzene-Methanol (20:80) Monomer concentration: $10 \%$.

could be observed in Figure 15. The gamma irradiation dose used was preferred to be $16 \mathrm{kGy}$ in order to reduce homopolymer formation.

From the foregoing results it was possible to choose the conditions that could be applied to prepare viscose rayon fabrics containing increasing graft yield. Thus, viscose rayon fabric samples in solvent system that can give the best graft yields together with $10 \%-15 \%$ of monomer were subjected to increasing gamma irradiation doses. The physicochemical properties of the grafted samples were then determined.

\subsection{Changes in the Physicochemical Properties of the Grafted Viscose Rayon Fabrics with Different Monomers as a Function of the Graft Yields (\%)}

\subsubsection{Moisture Absorption (\%) or Swelling (\%) of Viscose Rayon Grafted Fabrics}

Moisture absorption (\%) or swelling (\%) of viscose rayon fabrics grafted with methyl acrylate, acrylamide or acrylanitrile monomers in different solvent systems i.e. 
methanol/water or DMF/water were determined at different graft yields (\%). The results are shown in Figures 16-19.

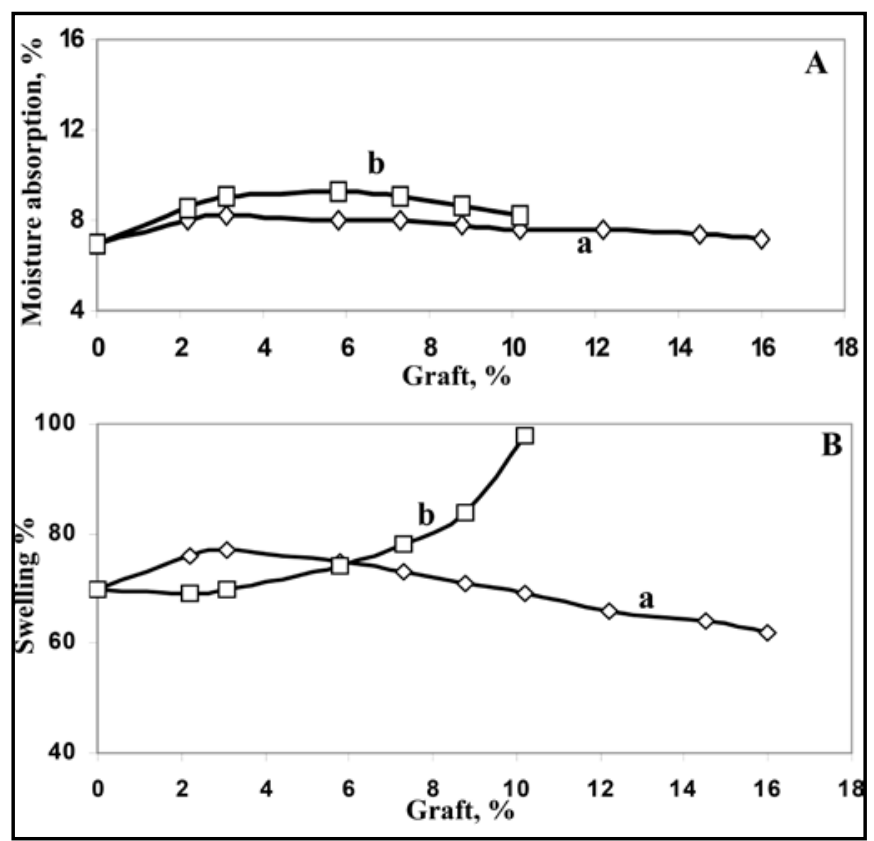

Figure 16. Change of Moisture absorption (\%), A and Swelling (\%), B of viscose rayon fabric grafted with methyl acrylate on using different solvent systems during the grafting process: a. Methanol$\mathrm{H}_{2} \mathrm{O}$ : (40:60); b. DMF-H2O: (40:60) Monomer concentration: $10 \%$; Irradiation dose: $1.0 \mathrm{KGy}$.

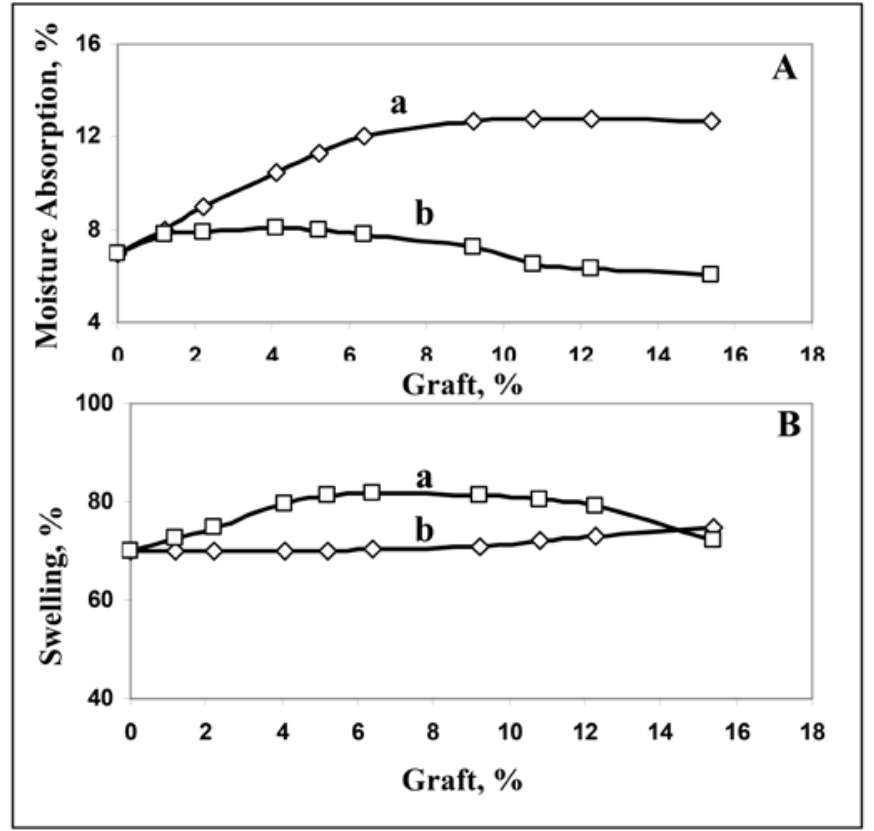

Figure 17. Change of moisture absorption (\%) A and swelling (\%) $\mathrm{B}$ on increasing the graft yield of acrylamide onto viscose rayon fabric using different solvent systems: a. methanol: $\mathrm{H}_{2} \mathrm{O}$ (80:20); b. DMF: $\mathrm{H}_{2} \mathrm{O}$ (80:20). Irradiation dose: $10 \mathrm{kGy}$. 


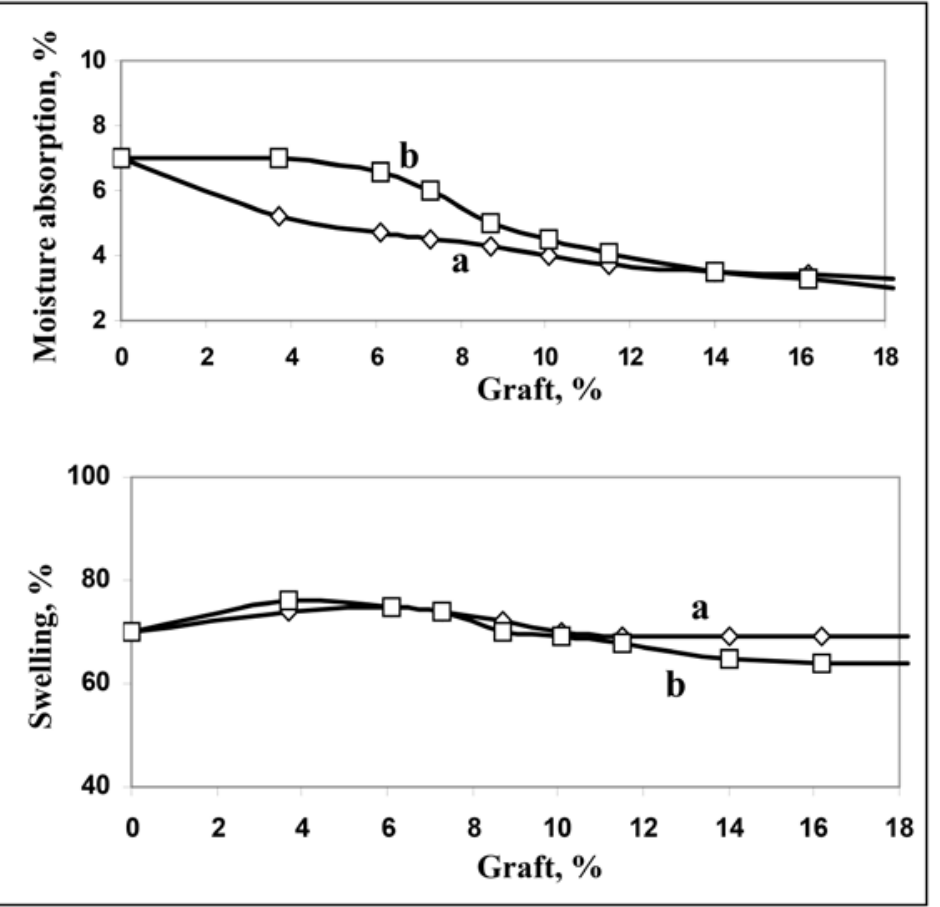

Figure 18. Change of moisture absorption (\%) and swelling (\%) with the graft yield (\%) of acrylonitrile onto viscose rayon fabric using two solvent systems during the grafting process: a. Methanol-Water: (70:30); b. DMF-Water: (70:30) Irradiation dose: $10 \mathrm{KGy}$.

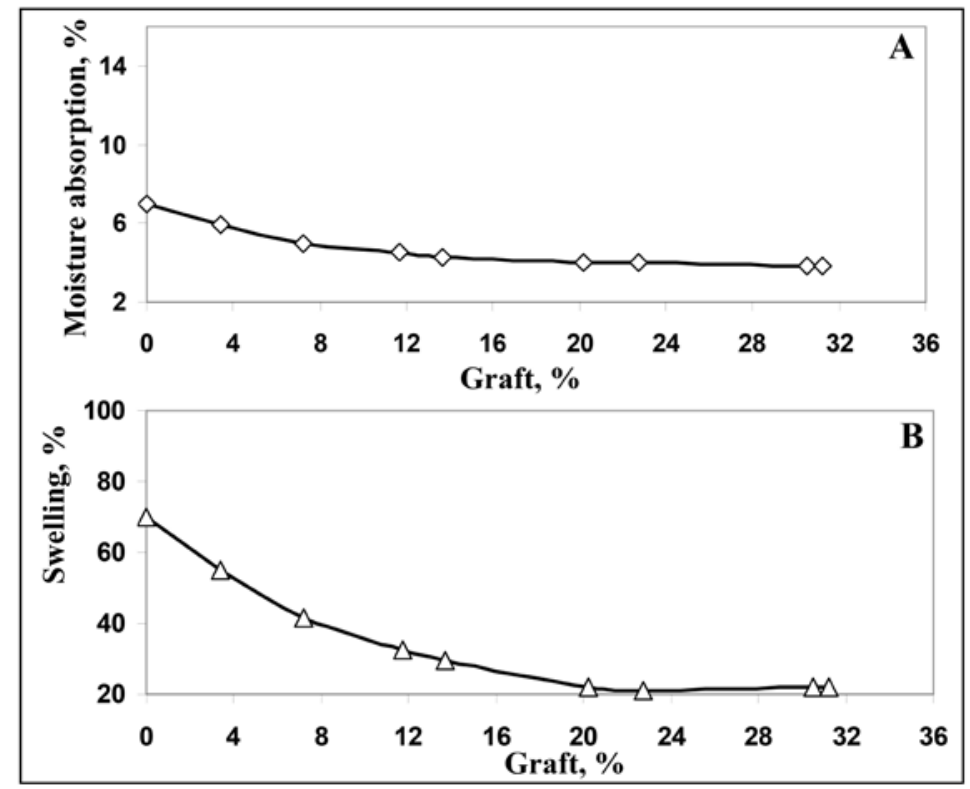

Figure 19. Change of the Moisture absorption (\%) A and swelling (\%) B with the graft yield (\%) of styrene onto viscose rayon fabric using benzenemethanol solvent $(20: 80)$ during the grafting process.

It could be observed that only minor changes occurred as the monomer graft yields (\%) onto viscose rayon fabrics increased.

Moisture absorption and swelling of viscose rayon fabric samples grafted on 
styrene in benzene/methanol solvent (20-80) showed a gradual decrease as the graft yield (\%) increased, as could be observed in Figure 19.

\subsubsection{Tensile Strength and Elongation}

The tensile strength (\%) and elongation at break of viscose rayon fabric samples grafted with different acrylic acid derivatives and with styrene were determined at different grafting yields. The results obtained are shown in Figures 20-23.

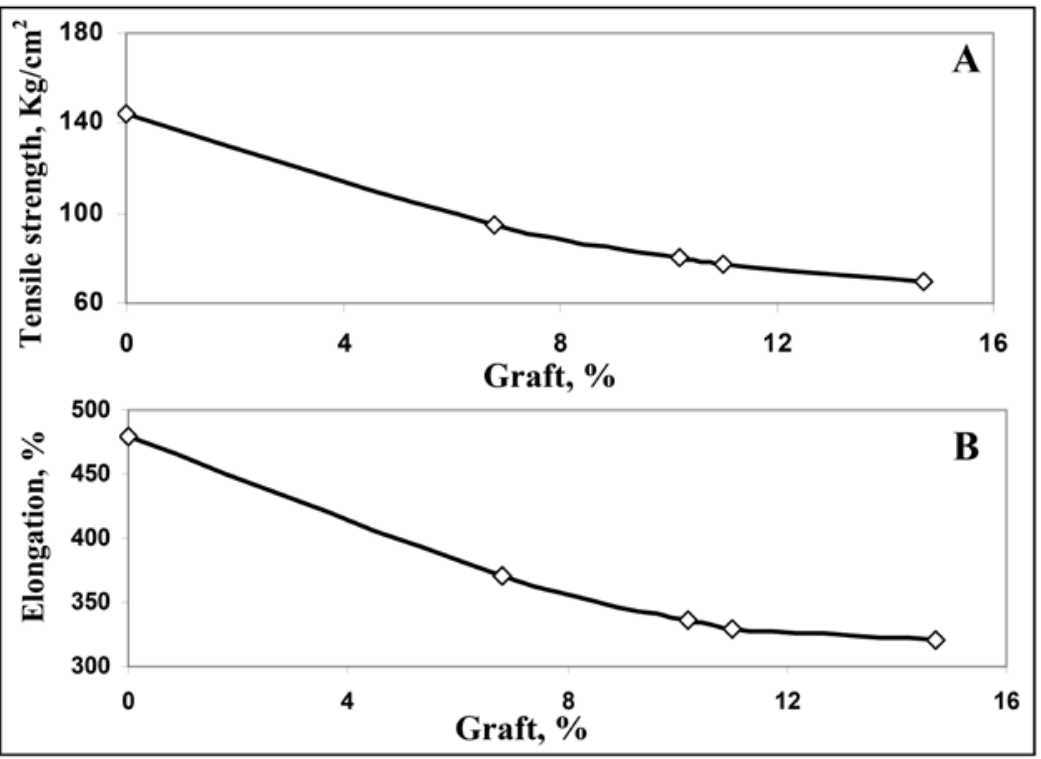

Figure 20. Change of Tensile strength and Elongation with the graft yield (\%) of methyl acrylate onto viscose rayon fabric samples.

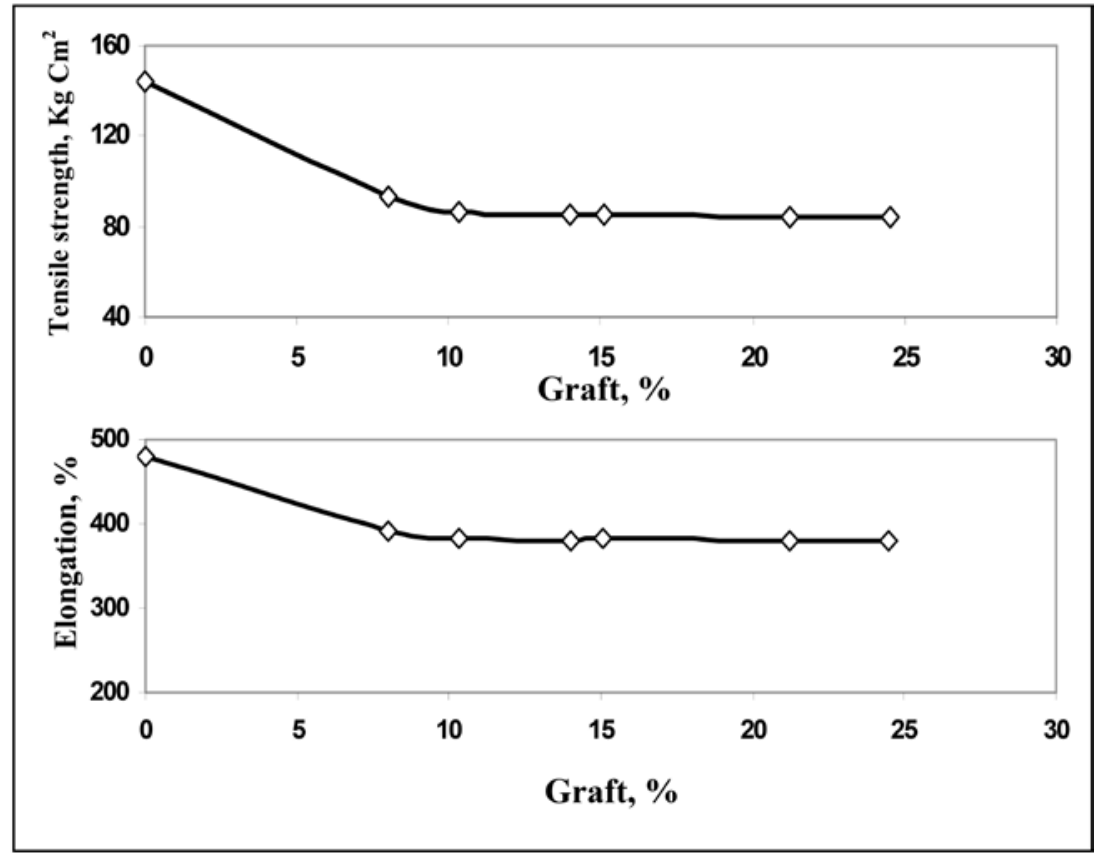

Figure 21. Change of tensile strength and elongation with the graft yield (\%) of acryla-mide onto viscose rayon fabric samples. 


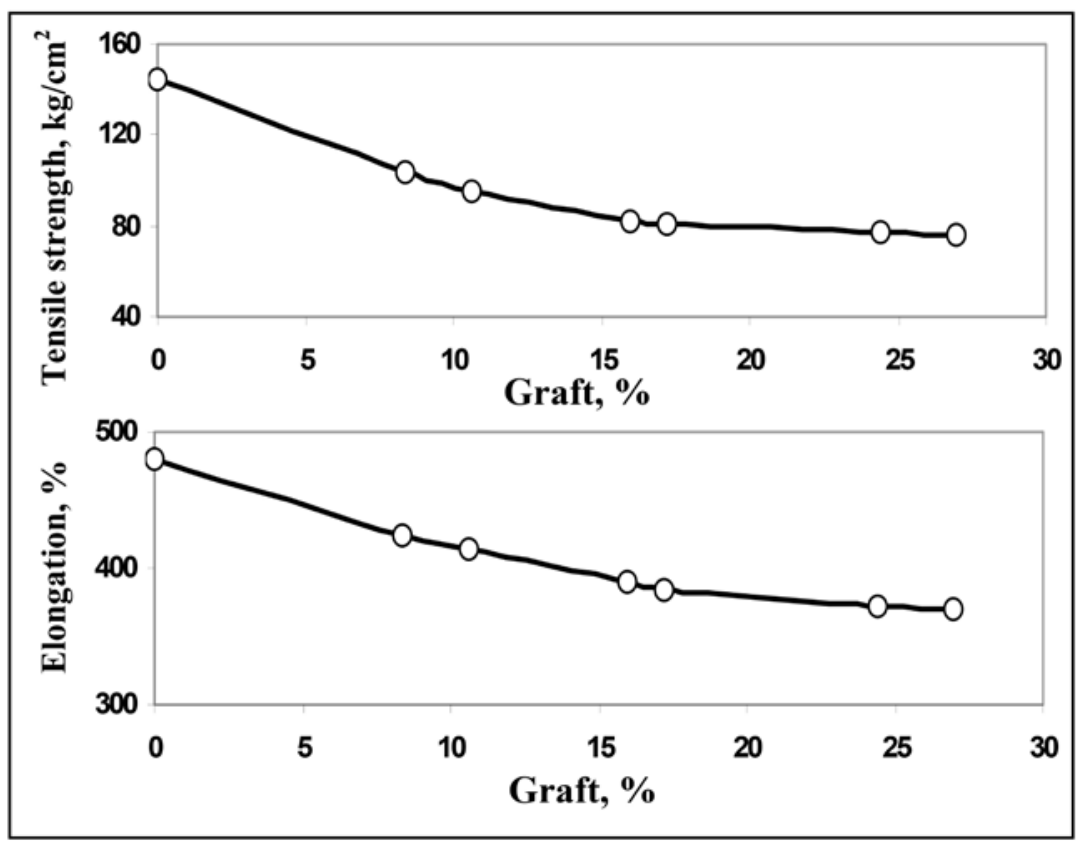

Figure 22. Change of the tensile strength and elongation at break with the graft yield (\%) of acrylonitrile grafted onto viscose rayon fabric samples.

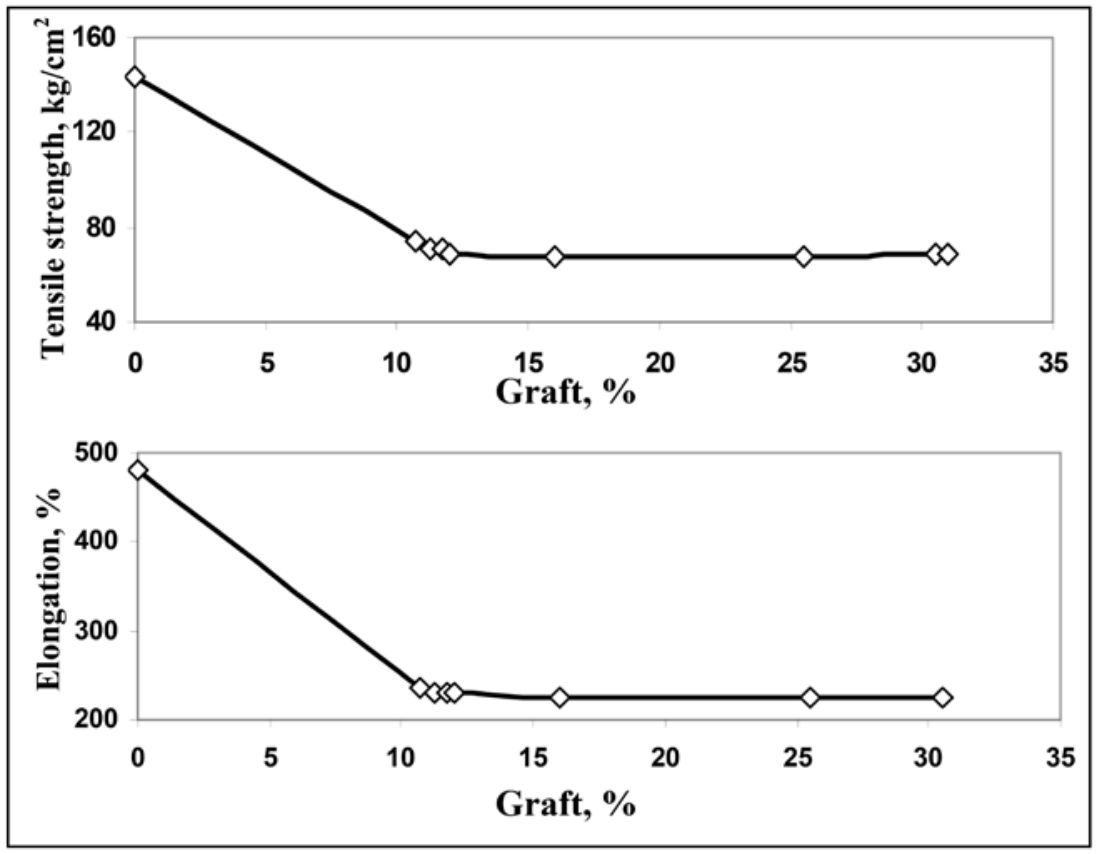

Figure 23. Change of Tensile strength and Elongation at break with the graft yield (\%) of styrene grafted onto viscose rayon fabric samples.

It could be observed both tensile strength and elongation at break values determined for the grafted samples decrease as the graft yields were increased up to $10 \%$ then remained almost the same as the graft yield was further increased. These results show that the tenacity of the viscose rayon fabrics increased with grafting. 


\subsubsection{Dyeing Ability of Grafted Viscose Rayon Fabric Samples}

In the present work, three types of dyes, a disperse dye; a direct dye and a basic dye were used with viscose rayon fabric samples grafted with acrylic acid derivatives and also with styrene. The change of the color strength of the grafted samples, due to dye uptake, with the corresponding graft yields has been studied.

Thus, on using a disperse dye with viscose rayon fabrics, grafted with methyl acrylate, the color strength of the dyed samples was rather low until the graft yield was about $7 \%$ then the color strength markedly increased on increasing the graft yields, as shown in Figure 24,a. In case of samples grafted with acrylamide or acrylonitrile no marked improvement in the dyeing ability was observed on increasing the graft yields, as could be observed in Figures 25,a and Figure 26,a. On the other hand, in case of viscose rayon fabrics grafted with styrene the color strength of the grafted samples markedly increased as the graft yield was increased (Figure 27,a).

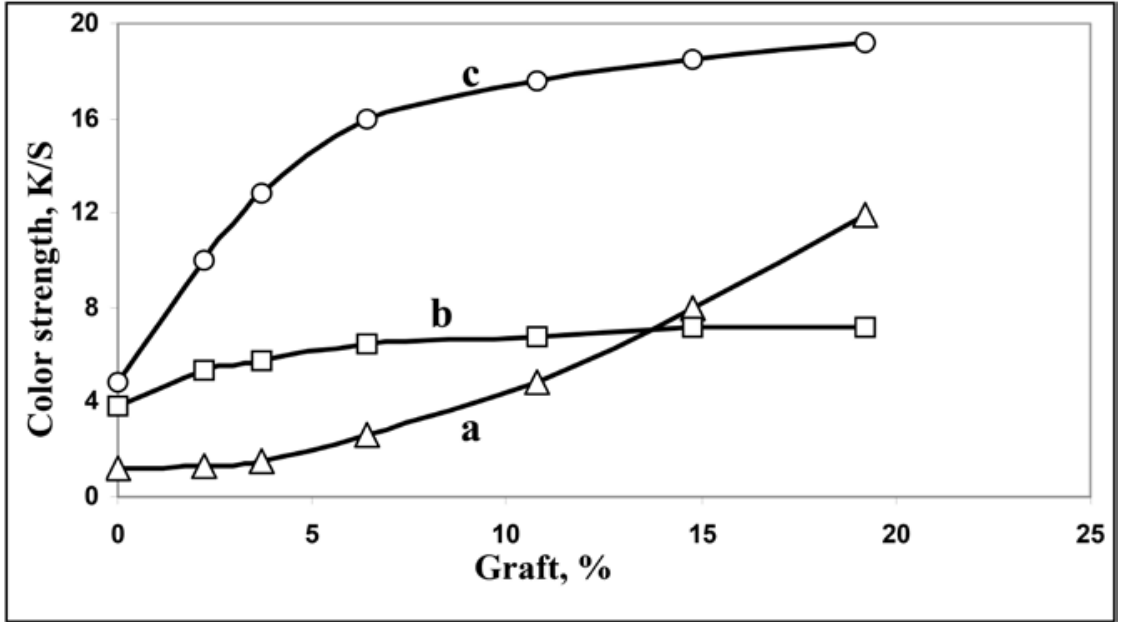

Figure 24. Change of the color strength of dyed viscose rayon samples, grafted with methyl acrylate, as a function of the graft yields (\%) using different dye types; a. Disperse dye; b. Direct dye; c. Basic dye.

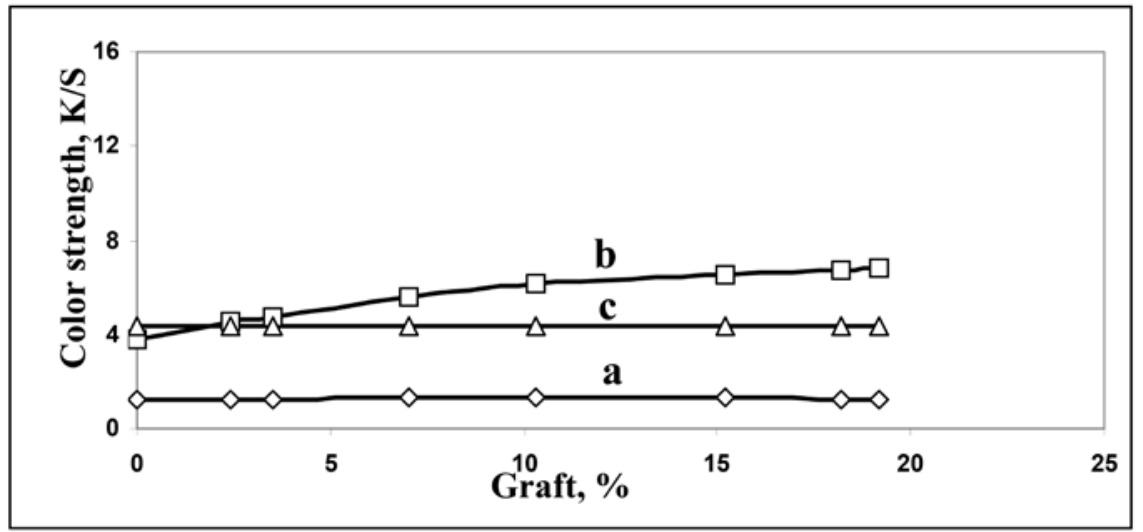

Figure 25. Change of the color strength of dyed viscose rayon samples, grafted with acrylamide monomer, as a function of the graft yields using different dye types: a. Disperse dye; b. Direct dye; c. Basic dye. 
On using the direct dye with viscose rayon fabrics grafted with methyl acrylate, acrylamide, acrylonitrile or styrene, the color strength of viscose rayon samples slightly increased on gradually increasing the graft yields up to about $10 \%$ and after that remained rather stable (Figures 24-27,b).

On using the basic dye with viscose rayon fabrics grafted with methyl acrylate, the color strength of the grafted samples was greatly improved on increasing the graft yields (Figure 24,c). In case of samples grafted with acrylamide the color strength of the dyed samples remained unaffected as the graft yields were increased (Figure 25,c). On using acrylonitrile monomer, the color strength of the grafted samples was almost doubled on increasing the graft yield to $10 \%$ and then remained the same as the graft yields was further increased (Figure 26,c). Grafting of viscose rayon fabrics with styrene greatly improved the dyeing ability of the grafted samples as could be observed in Figure 27,c.

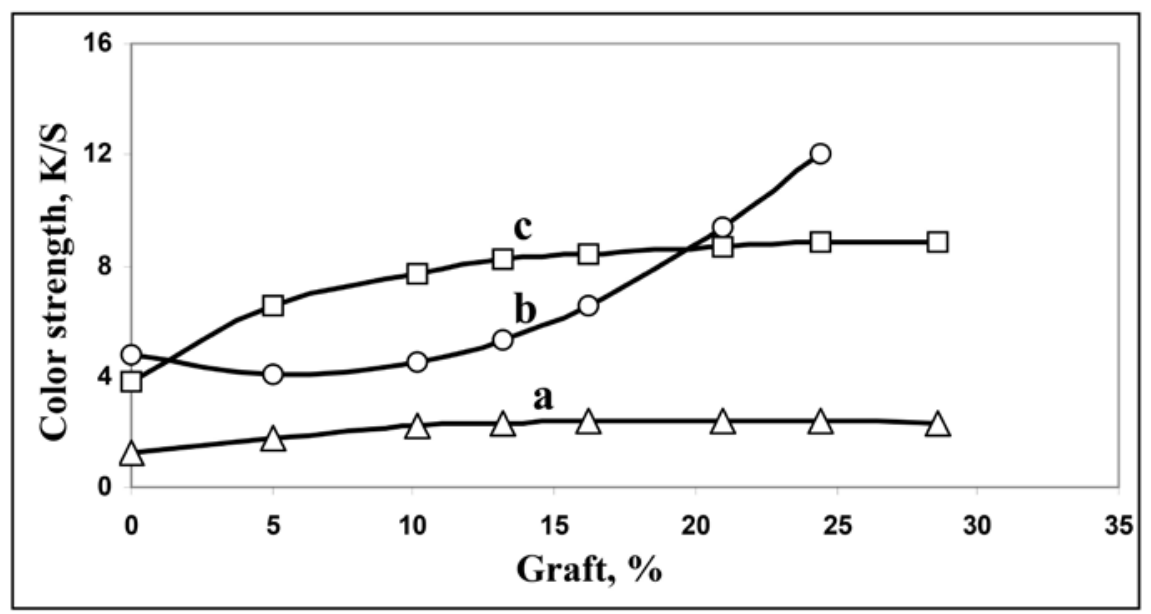

Figure 26. Change of the color strength of dyed viscose rayon samples grafted with acrylonitrile monomer as a function of the graft yields (\%) using different dye types; a. Disperse dye; b. Direct dye; c. Basic dye.

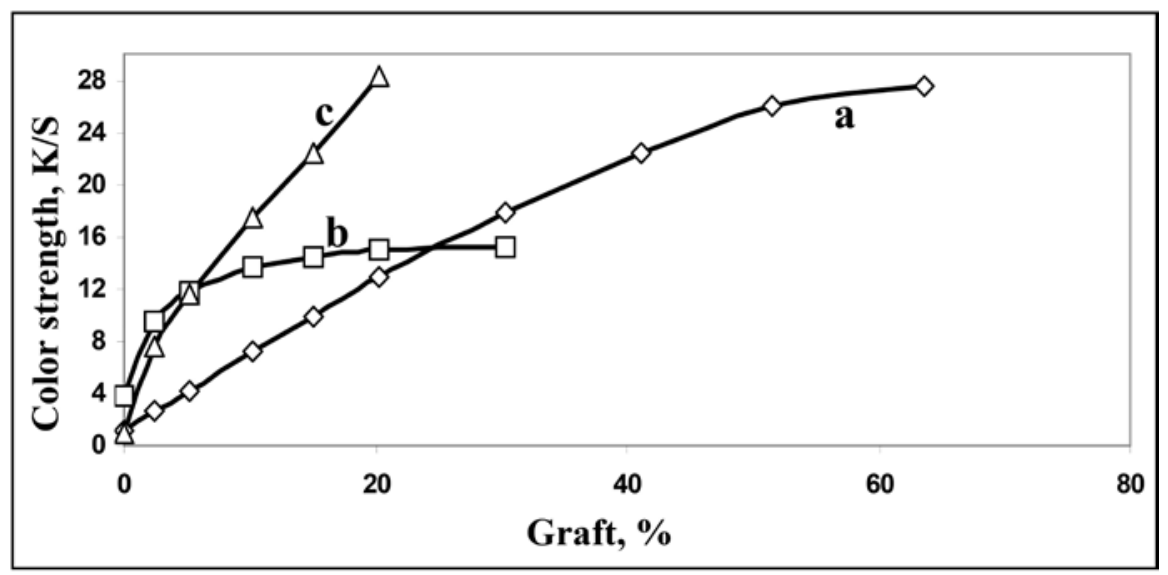

Figure 27. Change of the color strength of dyed viscose rayon samples grafted with styrene monomer, as a function of the graft yields (\%) using different dye types: a. Disperse dye; b. Direct dye; c. Basic dye. 


\subsubsection{Crease Recovery Angle}

The crease recovery angle of viscose rayon fabrics grafted with methyl acrylate or acrylamide was measured for different samples and plotted against the corresponding grafting yields.

On using methyl acrylate or acrylamide in grafting to viscose rayon fabrics, the crease recovery angle significantly increased on increasing the graft yields up to about 3\% then remained almost constant on further increasing the graft yields (Figure 28, Figure 29).

On using acrylonitrile the crease recovery angle showed a marked tendency to increase as the graft yield was increased, as could be observed in Figure 30. In case of viscose rayon fabrics grafted with styrene the crease recovery angle of the grafted samples was found to change sporadically around the value recorded for ungrafted samples (Figure 31).

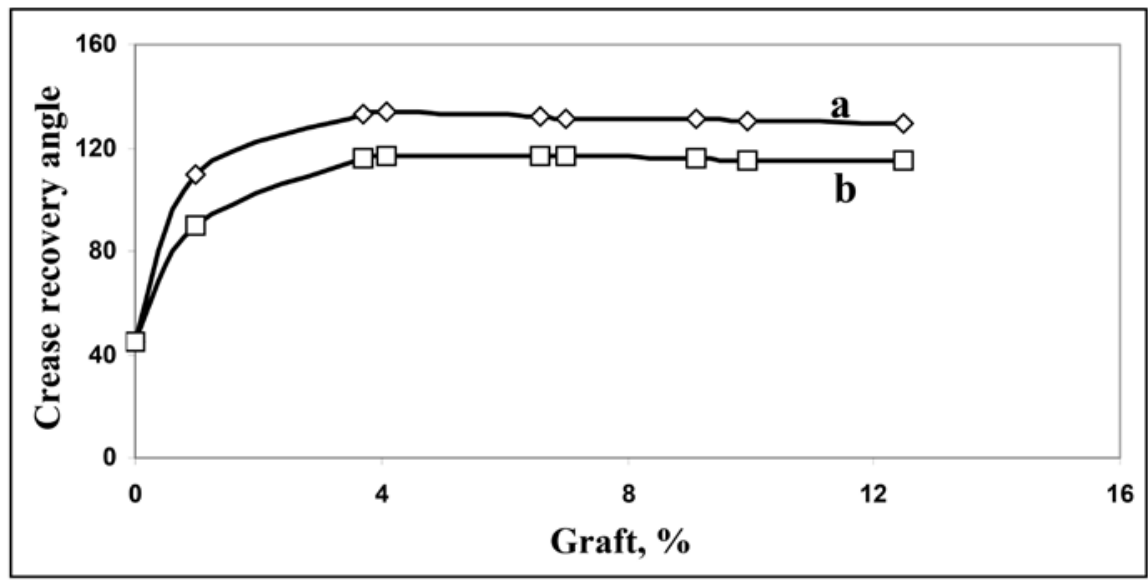

Figure 28. Change of the crease recovery angle of viscose rayon fabric samples, grafted with methyl acrylate monomer, with the graft yield (\%) in two directions: a. Warp direction; b. Weft direction.

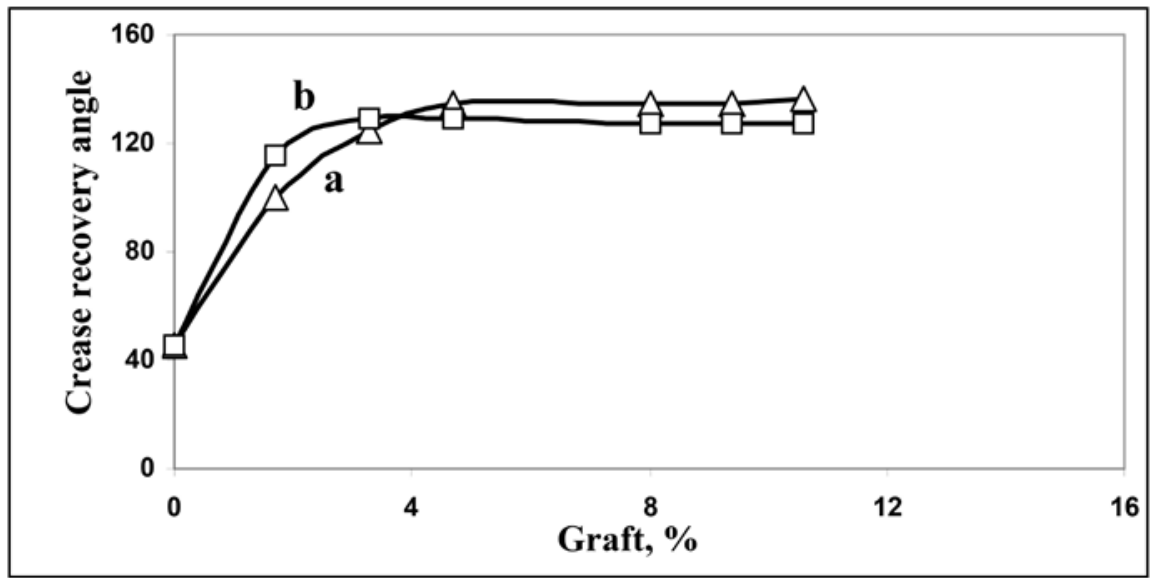

Figure 29. Change of the crease recovery angle of viscose rayon fabric samples, grafted with acylamide monomer, with the graft yield (\%) in two directions: $a$. Warp direction; $b$. Weft direction. 


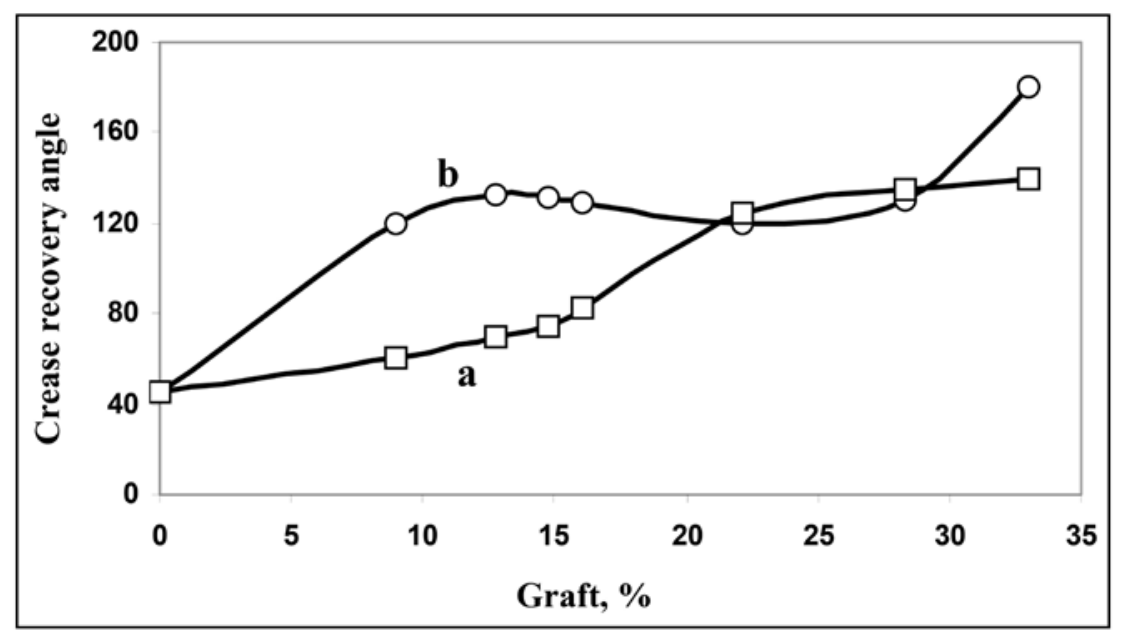

Figure 30. Change of the crease recovery angle of viscose rayon fabric samples, grafted with acrylonitrile monomer, with the graft yield (\%) in two directions: a. Warp direction; b. Weft direction.

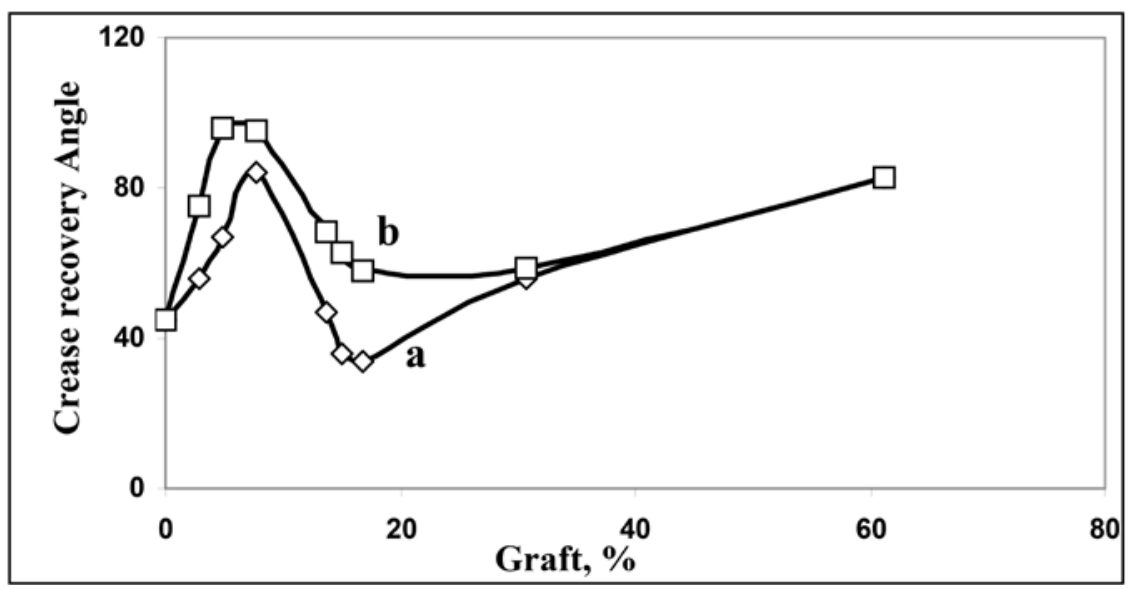

Figure 31. Change of the crease recovery angle of viscose rayon fabric samples, grafted with styrene monomer, with the graft yield (\%) in two directions: a. Warp direction; b. Weft direction.

\section{Conclusions}

1) Grafting of viscose rayon fabric samples with acrylic acid derivatives did not lead to marked changes in moisture absorption or swelling on increasing the graft yields on the grafted fabrics. On grafting with styrene a marked decrease in moisture absorption and swelling of the grafted samples was observed on increasing the graft yields.

2) The tensile strength and elongation at break of viscose rayon grafted samples with methyl acrylate, acrylamide, acrylonitrile or styrene were found to decrease gradually with graft yields until the graft yield became $10 \%$ then remained afterwards the same at higher graft yields.

3) Much better color strength was observed in case of viscose rayon fabric grafted with methyl acrylate or styrene, dyed with the basic dye as well as in case of styrene grafted viscose rayon, dyed with the disperse dye. 
The color strength of acrylonitrile or styrene grafted fabrics, dyed with the direct dye was found to improve markedly after the graft yield of acrylonitrile or styrene onto viscose rayon was about $10 \%$.

On dyeing viscose rayon fabric grafted with acrylamide and using the disperse, direct or basic dye, no improvement was observed in the dyeing ability of the grafted fabric with these dyes. The same applies in case of viscose rayon grafted fibers with methyl acrylate on using the disperse or direct dye. In case of viscose rayon grafted with acrylonitrile, very limited changes of the color strength of the grafted samples occurred on dying with the basic or disperse dye.

4) Crease recovery angle was improved significantly on grafting viscose rayon with methyl acrylate or acrylamide even at low grafting yields. In case of acrylonitrile the crease recovery angle was improved at higher grafting yield i.e. more than about $10 \%$, In case of grafting with styrene the crease recovery angle sporadically changed around a value that is twice the crease recovery angle of ungrafted samples.

\section{References}

[1] Shapiro, A. (1962) Radiation Chemistry of Polymeric Systems. Interscience Publishers, John Wiley and Sons, New York, 686.

[2] Krassig, H.A. and Stannett, V. (1965) Graft Copolymerization to Cellulose and Its Derivatives. Advances in Polymer Science, 4, 129-144.

[3] Gilbert, R.D. and Stanett, V. (1967) Use of High Energy Radiations for Modification of Textile Fibers. Isotopes Radiologic Technology, 4, 403.

[4] Misra, B.N., Kaur, I., Kapoor, B. and Lakhanpal, S. (1992) Gamma Radiation Induced Graft Copolymerization of Vinyl Monomers onto Rayon. Indian Journal of Fibre and Textile Research, 17, 107.

[5] El-Naggar, A.M., El-Salmawi, K., Ibrahim, S.M. and Zahran, A.H. (1997) Characterization of Preirradiation Grafting of Acrylamide onto Nylon-6 Fabric. Radiation Physics and Chemistry, 49, 287.

[6] Zahran, A.H., El-Hosamy, M.B. and El-Gendy, E. (1985) Radiation Induced Grafting of Acrylic Acid onto Nylon-6. American Dyestuff Reporter, 47, 34.

[7] Hsieh, Y., Potter, D. and Elson, M.S. (1984) In Situ Polymerization of Vinylpyrrolidinone on Nylon-66 by Gamma Radiations. Journal of Radiation Curing, 11, 6.

[8] Barakat, M.F., El-Salmawy, K.M. and Zahran, A.H. (2016) Radiation Induced Grafting of Acrylic Acid onto Viscose Rayon Fabrics and Its After-Effects. Open Journal of Polymer Chemistry, 6, 27. 
Submit or recommend next manuscript to SCIRP and we will provide best service for you:

Accepting pre-submission inquiries through Email, Facebook, LinkedIn, Twitter, etc. A wide selection of journals (inclusive of 9 subjects, more than 200 journals)

Providing 24-hour high-quality service

User-friendly online submission system

Fair and swift peer-review system

Efficient typesetting and proofreading procedure

Display of the result of downloads and visits, as well as the number of cited articles Maximum dissemination of your research work

Submit your manuscript at: http://papersubmission.scirp.org/

Or contact ojpchem@scirp.org 